University of Nebraska - Lincoln

DigitalCommons@University of Nebraska - Lincoln

Faculty Publications: Department of Teaching, Department of Teaching, Learning and Teacher Learning and Teacher Education

Education

3-2012

\title{
Obstacles to Addressing Race and Ethnicity in the Mathematics Education Literature
}

Amy Noelle Parks

University of Georgia, parksamy@msu.edu

Mardi Schmeichel

University of Georgia, mardi@unl.edu

Follow this and additional works at: https://digitalcommons.unl.edu/teachlearnfacpub

Part of the Curriculum and Instruction Commons, Science and Mathematics Education Commons, Social and Philosophical Foundations of Education Commons, and the Teacher Education and Professional Development Commons

Parks, Amy Noelle and Schmeichel, Mardi, "Obstacles to Addressing Race and Ethnicity in the Mathematics Education Literature" (2012). Faculty Publications: Department of Teaching, Learning and Teacher Education. 468.

https://digitalcommons.unl.edu/teachlearnfacpub/468

This Article is brought to you for free and open access by the Department of Teaching, Learning and Teacher Education at DigitalCommons@University of Nebraska - Lincoln. It has been accepted for inclusion in Faculty Publications: Department of Teaching, Learning and Teacher Education by an authorized administrator of DigitalCommons@University of Nebraska - Lincoln. 


\title{
Obstacles to Addressing Race and Ethnicity in the Mathematics Education Literature
}

\author{
Amy Noelle Parks and Mardi Schmeichel \\ University of Georgia
}

\begin{abstract}
This Research Commentary builds on a 2-stage literature review to argue that there are 4 obstacles to making a sociopolitical turn in mathematics education that would allow researchers to talk about race and ethnicity in ways that take both identity and power seriously. The obstacles discussed are (a) the marginalization of discussions of race and ethnicity; (b) the reiteration of race and ethnicity as independent variables; (c) absence of race and ethnicity from mathematics education research; and (d) the minimizing of discussions of race and ethnicity, even within equity-oriented work.
\end{abstract}

Key words: Equity/diversity; Race/ethnicity/SES; Research issues; Review of research; Social and cultural issues

In the most recent Journal for Research in Mathematics Education Equity Special Issue, Gutiérrez (2010) argued that it is currently both easy and difficult to attend to identity and power in mathematics education - easy because of a shared recognition of the importance of social contexts and difficult because work that explicitly deals with power and identity often is marginalized by funding agencies and publication outlets. In her editorial, Gutiérrez described a number of theoretical perspectives that would help mathematics educators make a sociopolitical turn, whichlike the sociocultural turn before it - would change the way researchers think about quality research in mathematics education. The purpose of this Research Commentary is to describe some of the discursive barriers to making such a turn, particularly around work that focuses on race and ethnicity. We chose to focus on race and ethnicity because, as Gutiérrez (2010, p. 5) wrote, "racism is a particularly prominent form" of hegemony in the United States, and because we wanted to narrow the scope of our review so we could look deeply as well as broadly. Throughout this Research Commentary, we use both race and ethnicity to be as

This Research Commentary is based in part upon work supported by the National Science Foundation under Grant No. 844445 to University of Georgia Research Foundation (Amy Noelle Parks, PI). Any opinions, findings, and conclusions or recommendations expressed herein are those of the authors and do not necessarily reflect the views of the National Science Foundation. In addition, we would like to thank David Stinson and the anonymous reviewers for thoughtful and productive comments on the manuscript. 
inclusive as possible with respect to the variety of ways researchers talk about commonly identified social and cultural groups (e.g., African Americans, Hispanics, Whites, Native Americans). Our goal is to acknowledge the importance of race and racism as key constructs in equity, while also recognizing the complexity lived by members of communities such as Latino/as, in which individual members may identify with different racial groups but may also feel that shared aspects of their identities (such as language or culture) are important sociopolitical markers.

Following Gutiérrez, we use the term sociopolitical as shorthand for research theories and perspectives that broadly seek to address issues of identity and power. Whether researchers are writing about power or power relations, sociopolitical theories encourage them to attend to the ways that cultural, social, and economic status impact human relationships, whether the focus is on question-asking in a single elementary classroom or the designing of large-scale national assessments. Similarly, a concern with identity (or in some theoretical traditions, subjectivity) indicates awareness that cultural markers such as race, ethnicity, gender, and class matter in making sense of human endeavors, in part because "these characteristics are the very markers used in society to determine power" (Gutiérrez, 2002, p. 154). We see the markers on which we focus in this analysis - race and ethnicity - as both socially constructed and socially real, drawing on Omi and Winant (2004) who, while rejecting biological definitions, argue that the effects of "race-thinking (and race acting)" (p. 9) are necessary objects of study.

Sociopolitical projects also support attention to racism, which can be understood as "both the ideology and practice of inferiorizing and excluding groups of people by virtue of their 'race,' bearing in mind that racial differences are socially constructed" (Ng, 2005, p. 43). Racism can inform analysis of a variety of contexts related to mathematics, including the documenting of microaggressions, such as a teacher assuming that a Black boy's book about physics must have been a stolen book (McGee \& Martin, 2011) or the analysis of more macro forces, such as the variety of privileges being White affords in most mathematics classrooms (Martin, 2009a). We want to describe some of the obstacles to highlighting identity and power in discussions of race and ethnicity with the goal of placing the burden for removing these obstacles on the mathematics education community as a whole rather than solely on the shoulders of those scholars whose work primarily deals with equity and social justice. This is important because it is members of the broad mathematics education community who - through our work as reviewers, editors, mentors, and grant panelists - serve as the gatekeepers who will ultimately decide just how difficult making this sociopolitical turn in mathematics education is going to be.

We do not see the use of sociopolitical theories as simply a theoretical move designed to broaden the community's research perspectives, but a vital step in paying off what Ladson-Billings (2006) has termed our education debt to children. This debt, Ladson-Billings argues, is the result of long-term and present-day economic, political, and social inequities, which are often related to race. The effects of this debt show up broadly in the opportunities and supports available to particular groups of children and also more narrowly in measures of mathematics 
achievement and participation (Lubienski \& Bowen, 2000).

There is some evidence that using theories that direct researchers' attention to identity and power within mathematics classrooms can address this education debt by creating positive consequences for children (Gutstein, 2003; Martin, 2009c; Stinson, 2006). At the most basic level, acknowledging the race and ethnicity of human participants in educational studies helps readers make appropriate sense of the findings. It was, for example, considered a breakthrough in medicine when researchers began to identify gender and examine its role in clinical studies rather than using "men as the standard" (Pinn, 2003, p. 397). Similarly, in order to make sensible recommendations about practice for teachers and schools, we need to, at a minimum, report the identities of participants in our research projects. Sociopolitical theories can also support researchers in identifying productive pedagogies in mathematics, particularly when these practices may fall outside the typical domain of mathematics teaching, including, for example, Boaler's (2006) work on counteracting status differences in mathematics classrooms and work by Taylor (2009) and Nasir (2000) on children's demonstrations of mathematical competence in nontraditional settings. Finally, sociopolitical research can also make salient social and cultural experiences that may impact students' success and failure in mathematics classrooms that studies more narrowly focused on particular pedagogies may miss, such as Martin's (2006) analysis of African American adults' experiences with mathematics.

We undertook this literature review in part as a result of a series of comments by reviewers of manuscripts submitted for publication or funding by the first author, a White woman who taught and conducts mathematics education research in classrooms in which minority students are in the majority. The second author, also a White woman, conducts research on equity issues, but usually not in mathematics education. The comments that follow were written by reviewers in response to three independent manuscripts. We chose to highlight these comments for three reasons: (a) all the work reviewed was accepted for publication or funding; (b) each sought to highlight the role of identity in relation to mathematical learning, particularly with respect to race; and (c) each described work in racially and ethnically diverse classrooms.

The paper is vastly improved, and the topic remains an important and timely one. I suggest you remove references to student ethnicity as that does nothing to enhance your main point.

Our suggestion is not necessarily that the author must find more data and analyze data more thoroughly to support these claims about language, race, and class. Rather, we suggest that the author redefine diversity in terms of differences in participatory styles.

How will (or do) we know if these findings (i.e., learning opportunities, strategies) differ for non-African American low-income students? Can the design accommodate "control" groups?

Although this collection of comments is idiosyncratic, they point to some of the difficulties that researchers who write about race in ways that take power and iden- 
tity seriously may experience. The first two comments suggest removing language that describes or analyzes race. The third comment frames studies about race and ethnicity as comparative and experimental. All these comments point to discursive challenges to writing about race and ethnicity in ways that acknowledge contradictions in various performances of race, value its social significance, and see identity as performance (for examples of work that achieves these goals, see Berry, 2008; Gutiérrez, 2010; Martin, 2006; Nasir, 2002; Turner, Gutiérrez, Simic-Muller, \& Diez-Palomar, 2009) and, if widespread, would present challenges to getting work through the review processes that draw on such critical perspectives.

\section{TRUTH THROUGH REINSCRIPTION}

We undertook our literature review based on the belief that if these sorts of comments are part of a wider (but difficult to document) discourse in mathematics education, then we would see evidence of limited ways of thinking about race in the kinds of work that does get published and that we would see little evidence of work that engaged with sociopolitical theories of power and identity. Although not the subject of this study, discourses around race and ethnicity are also present in a variety of social settings, such as mentoring relationships and informal conversations at conferences. For this exploration, however, we used published texts as one window into these broader discourses around race and ethnicity in mathematics education. The belief that discourses can be traced in this way comes out of a theoretical frame that sees truth as the product of continual reinscriptions in discourse (Foucault, 1980; Parks, 2009a; Walkerdine, 1988). That is, the more frequently certain ideas are produced in speech and writing, the more true they seem, and the less often certain ideas appear, the less possible they seem. Following Foucault, the production of knowledge is an exercise of power, which makes it possible for some concepts, ideas, and theories to be thought easily and for some concepts, ideas, and theories to be impossible (or nearly so) to be thought. Ideas are not seen as located within individual minds but as truths shared through retelling in communities. This viewpoint is central to this critique. We do not see the lack of attention to race and ethnicity in the field as the "fault" of individual researchers, but as the product of the discourses in which all of us are situated.

The writing done about race and ethnicity not only shapes the research available for scholars to make arguments but also shapes the broader discourses in which mathematics educators operate as they live and teach in the world. Dominant theories about race and ethnicity become ingrained for both writers and reviewers as they produce documents that seek to understand and explain the world, often without conscious recognition of the discourses that make those explanations possible and intelligible.

Drawing on this theoretical frame, we undertook a two-stage literature review to identify dominant discourses in mathematics education around race and ethnicity. In our first stage of review, we used the ERIC search engine to look across the field of mathematics education over the preceding 10 years. We chose ERIC both 
because of its search capabilities and because of its prominence, which meant that other researchers looking to write about race and ethnicity in mathematics education would be likely to locate similar articles. Building on the work of Lubienski and Bowen (2000), we began by creating a comprehensive list of ERIC descriptors related to mathematics $(n=46)$ and a comprehensive list of descriptors related to race and equity issues $(n=70) .{ }^{1}$ Using both sets of descriptors, we built a search to identify articles within the ERIC database that possessed at least one of the mathematics descriptors and at least one of the race or ethnicity descriptors. Because Lubienski and Bowen's study included scholarship published between 1982 and 1998, we limited our search to peer-reviewed journal articles published between January 1999 and June 2010.

To give some perspective about the volume of mathematics-related articles and the limited attention to race and ethnicity, consider the following data from our analysis: Since 2005, 8,326 peer-reviewed articles with one of our mathematics education descriptors were published. Of those, 320 articles included one of our 70 descriptors related to race and ethnicity, which put the percentage of race/ ethnicity related articles at just under $4 \%$. In all, we identified 403 peer-reviewed articles published since 1999 that met our search criteria of including at least one mathematics descriptor and one race or ethnicity descriptor. These articles were published in 191 different journals across the field of education. Because reading all these articles was outside of the scope of this project, our analysis of the articles retrieved in the ERIC search resulted in a primarily quantitative description of the way in which mathematics and race/ethnicity show up together in the field of education as a whole. For example, we classified articles as published within or outside of mathematics education and within or outside of particular subfields (such as teacher education).

To gain a more fine-grained sense of the ways to which race and ethnicity were or were not being attended in mathematics education research, we decided that we needed to examine the texts of recent articles, not simply database descriptors. To achieve a manageable but representative data set, we decided to review 3 years of research articles (2008-2011) published in JRME, the most prominent research journal in U.S. mathematics education. We reviewed all 46 research articles, ${ }^{2}$

\footnotetext{
${ }^{1}$ Descriptors are terms, assigned by the ERIC Lexicography staff, that label the major topics of an ERIC document. To build a list of mathematics education search terms, we used the ERIC thesaurus to find any descriptor related to mathematics. This list included terms such as algebra, mathematics anxiety, and elementary school mathematics. There were a handful of mathematical terms excluded from our search because they did not yield any mathematics education results. To compile the list of ERIC descriptors related to culture, ethnicity, and race, we used a similar process, using the ERIC thesaurus to search for individual terms that contained culture, ethnic, and race as roots. We then used the People and Cultures category in the ERIC Browse by Category function to add additional race- and ethnicity-related terms to our list. We also added equity-oriented terms such as achievement gap to the search. Finally, we sought out all descriptors that referred to specific racial and ethnic groups. Descriptors included in this list were terms such as racial factors, African American family, and ethnicity.
}

\footnotetext{
${ }^{2}$ The Equity Special Issue is currently online only at www.nctm.org/jrme/equity. Stinson's (2010) article is listed in both the special issue (Issue 0 ) and Issue 1 . We counted it only once.
} 
regardless of topic or key words, with the goal of seeing how authors attended to, or did not attend to, race and ethnicity in mathematics education articles on all topics. We read the methodology and theoretical framework of every article and, using Adobe Reader, searched every article for the words race, ethnicity, racism, diversity, equity, and participants. We extracted for deeper analysis all paragraphs about race and ethnicity from every article. In addition, we extracted all descriptions of participants for a close reading, whether or not these descriptions mentioned race and ethnicity. These texts were then sorted and classified to identify broad themes in the data set.

\section{OBSTACLES TO THE SOCIOPOLITICAL TURN IN MATHEMATICS EDUCATION}

Looking across both stages of analysis, we identified four broad obstacles in the mathematics education discourse to writing about race and ethnicity in ways that take identity and power seriously.

\section{The Marginalization of Race/Ethnicity Discussions}

Although many articles in mathematics education touch on the constructs of race and identity, few deeply explore these ideas, and those that do are often located at the margins of the field. One way this happens is through journals' use of special issues to address many equity-related topics. Of the 46 articles published in JRME over the last 3 years, five discussed race and ethnicity in significant ways, namely, going beyond a brief description of participants (Averill et al., 2009; Berry, 2008; Gutiérrez, 2010; Setati \& Moschkovich, 2010; Stinson, 2010). Three of these were published in the most recent special issue. This is not an argument against special issues devoted to equity (or other marginalized topics). These focused issues serve to spotlight important topics and provide space for researchers to begin and extend conversations that might not otherwise take place. However, if the conversations in these special issues do not spill over into regularly published issues, there are some troubling discursive consequences to consider. For example, members of the mathematics education community whose primary work is not centered on equity are less likely to read these articles when they are grouped together as an "equity special issue" than if they are placed between articles on proof and mathematical knowledge for teaching. The placement of these articles in a special issue could inadvertently send a signal that these articles may not be relevant or salient to the entire mathematics education community. In turn, this can make it more difficult to disseminate the sociopolitical theories and methods used in these articles (such as Critical Race Theory and post-structural analysis) that inform equity work broadly and race and ethnicity work in particular. This also may make it less likely that manuscripts drawing on these theories will receive productive reviews in other contexts and less likely that scholars who study other topics will draw on these theories to inform their own work. Additionally, special issues run the risk of contributing to the sense that "everyone" is talking about equity, even while the 
total number of articles published does not change. Again, our call is not to eliminate special issues, but to work toward ensuring that the topics, theories, and methods highlighted in special issues also are incorporated into published work more broadly.

Table 1 shows the breakdown of all articles we located in our ERIC search that included at least one mathematics and one race/ethnicity descriptor, categorized broadly by the topic of the journal. Only $11 \%$ of the total number of articles that addressed mathematics education and race and ethnicity were published in mathematics education journals, which indicates that conversations about mathematics education and equity during the last decade were more likely to occur outside mathematics education journals than within them. In addition, of these journals outside mathematics education, journals focused specifically on equity and particular demographic groups published $16 \%$ of the articles, which means a number of articles in the search appeared in journals with audiences who already were very likely to be interested in examining issues of equity and the experiences of children of color and familiar with more critical theories for analyzing race and ethnicity.

This is problematic both because this research is then less likely to inform the broader mathematics education community and because researchers seeking to do work on race and ethnicity within mathematics education are likely to see mathematics education journals as less welcoming outlets for their work, which maintains the lack of awareness of sociopolitical theories and methods in the community.

\section{Widespread Reiterations of Race/Ethnicity as an Independent Variable}

Our broad analysis of the field also demonstrated that a preponderance of the articles that met our search criteria were located within the sphere of psychology (18\% of published articles). The majority of these journals primarily publishes articles that draw on experimental paradigms. Taken as a body of work, the density of studies that conceptualize race as a variable contribute to a discourse of race as primarily an easily defined category to which one belongs and to which particular traits or outcomes can be assigned. This use of race often shows up in large studies that break down data by demographic characteristics such as race and gender, such as in Post and colleagues' (2010) study of the relationship among prior mathematics achievement, high school mathematics curricula, and postsecondary mathematics performance. The tendency to treat race as a simple category could be seen in many of the JRME articles that mentioned race or ethnicity. Of the 46 articles we read, only 20 mentioned race or ethnicity at all, and of those, 12 listed race/ethnicity only as one of many descriptors for the participants. In 4 articles, the only mention of race occurred in a table.

Acknowledging identity in quantitative work is important. However, the common use of race as a variable can contribute to the idea that this is the only way of making sense of identity. This is not to say that important equity work cannot be done in studies that use race or ethnicity as variables (e.g., see Steele \& Aronson's (1995) work on stereotype threat). However, because this treatment of race is so widespread 
Table 1

Location of Articles With Mathematics and Race/Equity Descriptors Published Since 1999

\begin{tabular}{lccc}
\hline \multicolumn{1}{c}{ Journal type } & $\begin{array}{c}\text { Number of journals } \\
\text { in category }\end{array}$ & $\begin{array}{c}\text { Number of } \\
\text { articles }\end{array}$ & $\begin{array}{c}\text { Percent of total } \\
\text { number of articles }\end{array}$ \\
\hline General education & 43 & 115 & $29 \%$ \\
$\begin{array}{l}\text { Psychology and related } \\
\text { research }\end{array}$ & 45 & 73 & $18 \%$ \\
$\begin{array}{l}\text { Equity and demographic } \\
\text { groups }\end{array}$ & 16 & 59 & $15 \%$ \\
Mathematics education & 16 & 43 & $11 \%$ \\
Other education journals & 22 & 30 & $7 \%$ \\
Policy & 7 & 20 & $5 \%$ \\
Higher education & 11 & 18 & $4 \%$ \\
Science and technology & 7 & 17 & $4 \%$ \\
Early childhood & 9 & 13 & $3 \%$ \\
International education & 4 & 11 & $3 \%$ \\
Teacher education & & 4 & $1 \%$ \\
\hline
\end{tabular}

Note: Despite the topic overlap, for purposes of analysis, each journal was categorized into only one of the categories in the table. The General Education category was used for journals with scopes too broad to be placed into one of the categories we had identified. The Other Education category was used for journals with narrow scopes that did not have enough similar publications to merit an additional category. We focused our analysis on the fieldspecific categories because the diversity of journals within these two categories made analytic claims unreliable without a more in-depth analysis of each of these journals, which was beyond the scope of this project.

in the discourse, it creates an expectation, or a discursive truth, that this is the way race and ethnicity should be discussed. In his critique of the treatment of race as a variable, Martin (2009a) writes: "Because of the way [race] is juxtaposed with a host of suspected explanatory variables for achievement and persistence outcomessocioeconomic status and parent education level, for example - race often takes on the meaning of a fixed, causal variable rather than a historically and politically contingent construct whose meanings are subject to resistance, contestation, and negotiation" (pp. 313-314).

When race and ethnicity are routinely accepted as simple categories that need no theorizing or explanation, there are a number of significant discursive consequences: In-depth discussions of race seem superfluous, comparisons of one group (usually with minority status) to another group (usually White people) appear to be the only way of understanding the importance of race and ethnicity, and texts 
that delve into the contradictory identities of people with similar racial and ethnic identifiers can be read as not talking about race/ethnicity at all, because members of a single category are portrayed as having different reactions to particular pedagogies or contexts. It is critical that the field support a greater number of studies that engage in complicated discussions of identity in relation to race and ethnicity, such as through the conceptualization of race and ethnicity as a performance (Omi \& Winant, 2004) or as constructs implicated by history and racism (Frankenstein, 1997).

\section{Absence of Race/Ethnicity as a Relevant Site for Analysis}

Although many studies did mention the race/ethnicity of participants briefly, many studies we reviewed in JRME did not identify the race/ethnicity of the participants or of the researcher(s). Of the 46 articles we reviewed, 26 did not mention - even briefly - the race or ethnicity of participants. In many cases this was true even in well-designed, engaging studies with fairly robust descriptions of participants and the social context. For example, one study describes the ways that children take up knowledge of fractions in various settings, drawing on a theory of literacy as a "set of social practices that people use in certain situations or events" (Johanning, 2008, p. 284). The description of participants in this study reveals that students moved across grade levels, that students had experiences with a particular curriculum over 2 years, that students routinely engaged in mathematical conversations, and that teachers had robust mathematical and pedagogical knowledge. However, the identities of teachers and students in relation to race and ethnicity are not acknowledged. Similarly, a study of the impact of professional development on the selection and implementation of tasks (Boston \& Smith, 2009) does not mention the race and ethnicity of either the teachers who participated in the study or of the students whom the teachers taught. The study does give information about years of experience teaching, grade level taught, and whether the teachers were certified in secondary mathematics.

Although we chose these two studies to provide specific examples, they did not differ in any significant way from the other 24 studies that described participants without reference to race and ethnicity, except perhaps by providing more description of participants. In fact, we chose these two studies because we perceived them to be of particularly high quality: Our goal is not to critique individuals but rather the community standards. When again and again, race and ethnicity are portrayed as irrelevant to understanding social interactions and learning environments, this becomes more inscribed in the discourse. As a result, it becomes easier and easier to write about human interactions involving mathematics without discussing the ways that they may be impacted by discourses of race and ethnicity. Failing to make any reference to these topics also contributes to an intellectual environment in which reviewers may call for the removal of discussions of race and ethnicity from articles about mathematics education because these are seen as irrelevant (as was the case in two of the reviews quoted previously in this Research Commentary). This, in turn, contributes to the production of more articles that do not acknowledge 
the roles of race and ethnicity. For example, there is no way of knowing which articles we reviewed had discussions of race and ethnicity when they were submitted that were later cut to comply with reviewer or editor feedback, nor is it possible to know how many authors structured participant sections without reference to race and ethnicity based on their readings of previously published models in $J R M E$ that lacked discussion of race and ethnicity. For these reasons, it is important for us to be explicit that the broader discursive community (of which we are all members) has created these expectations for how race and ethnicity will be addressed and reported in mathematics education research.

As a widespread phenomenon, the failure to acknowledge bodies as raced (and classed and gendered) creates a number of consequences. First, it places an additional burden on researchers who want to write about identities in detailed and political ways, because they must use valuable space to justify why this matters. In contrast, writers who omit information about identity are not required to use manuscript space to justify why this information has been omitted. The expectation in the field seems to be that race and ethnicity do not matter unless one can prove otherwise. Second, choosing not to describe the race and ethnicity of participants in a study contributes to a sense of whiteness as normal and perpetuates the idea that we live in a society that is color-blind. That is, participants are assumed to be White unless they are described otherwise, and research findings are assumed to be relevant to all populations, regardless of the characteristics of study participants (much like medical research that assumed that studies of heart disease in men were equally relevant for women). Authors of studies with only White participants may not feel obligated to mention race, which contributes to a discourse in which only some people (often those with dark skin) are seen as having a race. In this way, the field of mathematics education could be considered to be one in which racial identity has received consistent attention, recognizing that this attention has been focused almost exclusively on children with White racial identities and, in doing so, often has normalized White children and White teachers' experiences while pathologizing the experiences of others.

\section{Minimizing of Race/Ethnicity in Equity Discussions and Analysis}

The final obstacle we want to discuss is the most subtle and occurred only when there was recognition already of the importance of equity work and identity. When we looked closely at some of the JRME articles that did mention race, ethnicity, and equity, we found a tendency for these topics to be referred to in a way that minimized discussions of race and ethnicity. Following Gutiérrez (2010) and Martin (2009a), we believe that creating a sociopolitical turn in mathematics education will require more than the acknowledgment of raced bodies. There also must be a conscious effort in at least some work at the center of the field to refrain from glossing over aspects of race and ethnicity that may be difficult to address and from writing about equity without seriously attending to ways that identity and power impact our work.

In our reading of the $J R M E$ articles, we found that some studies that acknowl- 
edged the importance of equity work did so in cursory ways. Although we want to celebrate the effort to acknowledge the importance of this topic, we also want to contribute to expectations that we all go deeper with our writing and thinking. For example, Hackenberg (2010), in her study of mathematical caring relations, calls for future studies to address the impact of race, gender, and class on such relationships with students from "diverse" backgrounds without giving an in-depth description of the context of her own work. Such mentions of race, ethnicity, and broader equity work can work against the apparent goal of increasing attention to equity issues, because they can contribute to the idea that equity talk is "everywhere" without doing significant analysis related to identity and power.

Race and ethnicity, in particular, often have been difficult for many White Americans to address when speaking and writing (Bonilla-Silva, 2006; Trepagnier, 2001) even within equity contexts (the current authors included). Many White teacher educators, teachers, and preservice teachers feel more comfortable talking about differences in gender, language, or "participatory style" (as in the case of one of the reviewers in the excerpts presented previously). Beyond talking about race, talking about racism is even more difficult. Only 2 of the $46 J R M E$ articles that we read explicitly mentioned racism. The ERIC search engine does not use "racism" as a descriptor; however, when we searched the 403 articles in our broad data set for the descriptors "racial bias" and "racial discrimination," we identified 9 articles with at least one of those descriptors, with only 1 published in a mathematics education journal. And yet, to fully acknowledge the way that power operates in a U.S. classroom, we must write about racism as well as race. As readers and reviewers of each other's work, we need to remind each other of this necessity and support each other in taking up the risky work of writing about race, ethnicity, and racism.

In this spirit, we call attention to an insightful analysis of identity in the mathematics classroom (Cobb, Gresalfi, \& Hodge, 2009). This article uses a fine-grained analysis of a single group of students in two different mathematics classrooms to explore the ways that mathematical identities shift in different contexts. The theoretical framework of the study draws on Martin's (2000) analysis of identity, which links broader sociohistorical issues to mathematical identities in the classroom. Although Cobb and colleagues describe the race of the participants as well as the ways that identity is shaped by teachers' and students' exercising of power in the classroom, the authors could have been supported in doing a deeper analysis of race by calls from reviewers to explicitly discuss the role of race in relation to specific findings in the study. For example, the authors report that five White students dropped out of the study because they lacked the time to participate, but do not discuss the result: a design class that had a majority of African American students, which, based on the reported demographic information, would have been an anomaly in the school. In addition, race is not theorized in relation to the four students (of unknown race) who described themselves as successful in the algebra class or to the one student (also of unknown race) described as successful in the algebra class by most participants. All of these data points are ripe for an analysis of mathematics as a racialized experience, even if one remains focused on 
classroom-level analysis, and one might expect that a study drawing on Martin's work (Martin, 2000; 2006; 2009b) would delve deeply into such issues. The authors do point out, correctly, that studies do not need to provide a "complete, allembracing explanation" (Cobb et al., 2009, p. 65) to be valuable, and argue that analyzing sociohistorical and community contexts would add important context to the study. We agree, and we believe that, as it stands, this piece makes a substantial contribution to mathematics education. However, we want to emphasize the discursive pull in this field that pulls researchers away from discussions of race and equity and toward other topics, even when researchers acknowledge the importance of "taking sociohistorical processes seriously" (Cobb et al. 2009, , p. 64).

\section{CONCLUSION}

Many studies published in mathematics education, including both those that discuss race and ethnicity in some way and those that do not, have worked to create a dominant discourse around race and ethnicity that emphasizes within-group similarities and downplays power relations, shifting identities, and recognition of race and ethnicity in diverse contexts. The choices of research topics, ways in which participants are (and are not) described, and contexts in which work is done together help to write mathematics education as a "white institutional space" (Martin, 2009a,b,c???, p. 10) where White perspectives become the norm. (This phenomenon is, of course, related to the fact that much of the writing has been done by White scholars.) Within this discourse, then, it becomes difficult for researchers to write from the perspectives of minority children and teachers, to recognize the ways in which students and families with similar racial or ethnic identities experience and live in the world differently (Martin, 2006), and to see race and ethnicity as relevant in studies that do not make population generalizations or seek to describe a particular culture. In fact, the first author, despite her familiarity with sociopolitical theories and commitment to equity goals, has sometimes failed to do the very things we call for here, such as theorizing race in relation to classroom social contexts (Parks, 2009b) and exploring the role of racism in classroom interactions (Parks, 2010). Attending to the complexity of race, ethnicity, and racism in research is difficult work and unlikely to be achieved without broad attention from the field.

The marginalization or exclusion of attention to race and ethnicity in mathematics education discourse is problematic because what we write both reflects and shapes what we know and believe to be true about the field. The absence of engagement with ideas of power, identity, and equity in mathematics education research reiterates a regulatory schema (Butler, 1993) that inhibits thinking about these forces as relevant to learning in the mathematics classroom and, by extension, limits our capacity for thinking about power and identity in ways that can make a difference for students. In order to achieve change, the field must begin speaking and writing about race and ethnicity in new ways. If attention to equity and the use of critical theories continue to be sidelined, there is no expectation for these ideas to be taken up more broadly in the field. Until the responsibility is more 
widely accepted and shared, these ideas are unlikely to propagate.

Again, the intention of this Research Commentary has not been to assign blame to particular individuals, and it does not come from certainty about the correct path forward. Rather, it comes from sadness about our schools' current and historical failure to meet the needs of all students, urgency to address this need, and hope that we can, as a community, make as much of our research as possible relevant to the task. Our goal has been to describe the discursive environment in which we all function and, therefore, for which we all share responsibility for maintaining and which we all must work to change.

\section{REFERENCES}

Averill, R., Anderson, D., Easton, H., Te Maro, P., Smith, D., \& Hynds, A. (2009). Culturally responsive teaching of mathematics: Three models from linked studies. Journal for Research in Mathematics Education, 40, 157-186. http://www.nctm.org/publications/toc.aspx?jrnl=jrme

Berry, R. Q., III. (2008). Access to upper-level mathematics: The stories of successful African American middle school boys. Journal for Research in Mathematics Education, 39, 464-488. http://www .nctm.org/publications/toc.aspx?jrnl=jrme

Boaler, J. (2006). How a detracked mathematics approach promoted respect, responsibility, and high achievement. Theory Into Practice, 45, 40-46. doi:10.1207/s15430421tip4501_6

Bonilla-Silva, E. (2006). Racism without racists: Color-blind racism and the persistence of racial inequality in the United States (2nd ed.). New York, NY: Rowman \& Littlefield.

Boston, M. D., \& Smith, M. S. (2009). Transforming secondary mathematics teaching: Increasing the cognitive demands of instructional tasks used in teachers' classrooms. Journal for Research in Mathematics Education, 40, 119-156.

Butler, J. (1993). Bodies that matter: On the discursive limits of "sex." London, England: Routledge.

Cobb, P., Gresalfi, M., Hodge, L. L. (2009). An interpretive scheme for analyzing the identities that students develop in mathematics classrooms. Journal for Research in Mathematics Education, 40, 40-68. http://www.nctm.org/publications/toc.aspx?jrnl=jrme

Foucault, M. (1980). Power/knowledge: Selected interviews and other writings, 1972-1977 (C. Gordon, Ed.). New York, NY: Pantheon.

Frankenstein, M. (1997). In addition to the mathematics: Including equity issues in the curriculum. In J. Trentacosta \& M. J. Kenney (Eds.), Multicultural and gender equity in the mathematics classroom: The gift of diversity (pp. 10-22). Reston, VA: National Council of Teachers of Mathematics.

Gutiérrez, R. (2002). Enabling the practice of mathematics teachers in context: Toward a new equity research agenda. Mathematical Thinking and Learning, 4, 145-187.

Gutiérrez, R. (2008). A "gap-gazing" fetish in mathematics education? Problematizing research on the achievement gap. Journal for Research in Mathematics Education, 39, 357-364. http://www.nctm .org/publications/toc.aspx?jrnl=jrme

Gutiérrez, R. (2010). The sociopolitical turn in mathematics education. Journal for Research in Mathematics Education Special Equity Issue. http://www.nctm.org/publications/toc.aspx? $\mathrm{jrnl}=\mathrm{JRME} \& \mathrm{mn}=6 \& \mathrm{y}=2010$

Gutstein, E. (2003). Teaching and learning mathematics for social justice in an urban, Latino school. Journal for Research in Mathematics Education, 34, 37-73. http://www.nctm.org/publications/ toc.aspx?jrnl=jrme

Hackenberg, A. J. (2010). Mathematical caring relations in action. Journal for Research in Mathematics Education, 41, 236-273.

Johanning, D. I. (2008). Learning to use fractions: Examining middle school students' emerging fraction literacy. Journal for Research in Mathematics Education, 39, 281-310. http://www.nctm.org/ publications/toc.aspx?jrnl=jrme

Ladson-Billings, G. (2006). From the achievement gap to the education debt: Understanding achievement in U.S. schools. Educational Researcher, 35(7), 3-12. doi:10.3102/0013189X035007003 
Lubienski, S. T., \& Bowen, A. (2000). Who's counting? A survey of mathematics education research 1982-1998. Journal for Research in Mathematics Education, 31, 626-633. http://www.nctm.org/ publications/toc.aspx?jrnl=jrme

Martin, D. B. (2000). Mathematics success and failure among African-American youth: The roles of sociohistorical context, community forces, school influence, and individual agency. Mahwah, NJ: Erlbaum.

Martin, D. B. (2006). Mathematics learning and participation as racialized forms of experience: African American parents speak on the struggle for mathematics literacy. Mathematical Thinking and Learning, 8, 197-229. doi:10.1207/s15327833mt10803_2

Martin, D. B. (2009a). Researching race in mathematics education. Teachers College Record, 111, 295-338. http://www.tcrecord.org

Martin, D. B. (2009b). Liberating the production of knowledge about African American children and mathematics. In D. B. Martin (Ed.), Mathematics teaching, learning and liberation in the lives of Black children (pp. 3-36). New York, NY: Routledge.

Martin, D. B. (Ed.). (2009c). Mathematics teaching, learning, and liberation in the lives of Black children. New York, NY: Routledge.

McGee, E., \& Martin, D. B. (2011). From the hood to being hooded: A case study of a Black male PhD. Journal of African American Males in Education, 2(1), 46-65. http://journalofafricanamericanmales.com

Nasir, N. S. (2000). "Points ain’t everything": Emergent goals and average and percent understandings in the play of basketball among African-American students. Anthropology \& Education Quarterly, 31, 283-230. doi: 10.1525/aeq.2000.31.3.283

Nasir, N. S. (2002). Identity, goals, and learning: Mathematics in cultural practice. Mathematical Thinking and Learning, 4, 213-247. doi:10.1207/S15327833MTL04023_6

Ng, R. (2005). Postscript. In J. Lee \& J. Lutz (Eds.), Situating “race” and racisms in time, space, and theory: Critical essays for activists and scholars (pp. 42-44). Montreal, Canada: McGill-Queen's University Press.

Omi, M., \& Winant, H. (2004). On the theoretical status of the concept of race. In G. Ladson-Billings \& D. Gillborn (Eds.), The RoutledgeFalmer reader in multicultural education (pp. 7-15). London, England: RoutledgeFalmer.

Parks, A. N. (2009a). Doomsday device: Rethinking the deployment of the "achievement gap" in equity arguments. For the Learning of Mathematics, 29(1), 14-19.

Parks, A. N. (2009b). Can teacher questions be too open? Teaching Children Mathematics, 15, 424428. http://www.nctm.org/publications/tcm.aspx

Parks, A. N. (2010). Explicit versus implicit questioning: Inviting all children to think mathematically. Teachers College Record, 112, 1871-1896. http://www.tcrecord.org

Pinn, V. W. (2003). Sex and gender factors in medical studies: Implications for health and clinical practice. Journal of the American Medical Association, 289, 397-400.

Post, T. R., Medhanie, A., Harwell, M., Norman, K. W., Dupuis, D. N., Muchlinski, T., . . , \& Monson, D. (2010). The impact of prior mathematics achievement on the relationship between high school mathematics curricula and postsecondary mathematics performance, course-taking, and persistence. Journal for Research in Mathematics Education, 41, 274-308. http://www.nctm.org/ publications/toc.aspx?jrnl=jrme

Setati, M., \& Moschkovich, J. N. (2010). Mathematics education and language diversity: A dialogue across settings. Journal for Research in Mathematics Education Special Equity Issue. http://www.nctm.org/publications/toc.aspx?jrnl=JRME\&mn=6\&y=2010

Steele, C. M., \& Aronson, J. (1995). Stereotype threat and the intellectual test performance of African Americans. Journal of Personality and Social Psychology, 69, 797-811. doi:10.1037/ 0022-3514.69.5.797

Stinson, D. W. (2006). African American male adolescents, schooling (and mathematics): Deficiency, rejection, and achievement. Review of Educational Research, 76, 477-506. doi: $10.3102 / 00346543076004477$

Stinson, D. (2010). Negotiating the "White Male Math Myth": African American male students and success in school mathematics. Journal for Research in Mathematics Education Special Equity Issue. http://www.nctm.org/publications/toc.aspx?jrnl=JRME\&mn=6\&y=2010 
Taylor, E. V. (2009). The purchasing practice of low-income students: The relationship to mathematical development. The Journal of the Learning Sciences, 18, 370-415. doi:10.1080/10508400903013462

Trepagnier, B. (2001). Deconstructing categories: The exposure of silent racism. Symbolic Interaction, 24, 141-163. doi:10.1525/si.2001.24.2.141

Turner, E. E., Gutiérrez, M. V., Simic-Muller, K., \& Diez-Palomar, J. (2009). "Everything is math in the whole world": Integrating critical and community knowledge in authentic mathematical investigations with elementary Latina/o students. Mathematical Thinking and Learning, 11, 136-157. doi:10.1080/10986060903013382

Walkerdine, V. (1988). The mastery of reason: Cognitive development and the production of rationality. London, England: Routledge.

\section{Authors}

Amy Noelle Parks, Elementary and Social Studies Education, University of Georgia, 629 Aderhold Hall, Athens, GA, 30602; amyparks@uga.edu.

Mardi Schmeichel, Elementary and Social Studies Education, University of Georgia, 629 Aderhold Hall, Athens, GA, 30602; mardi@uga.edu.

Accepted October 13, 2011 